\title{
Affinity improvement of the fully human anti-TSLP recombinant antibody
}

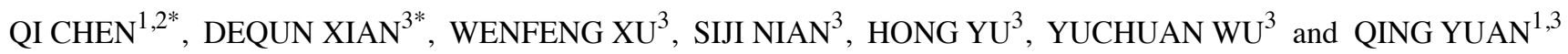 \\ ${ }^{1}$ State Key Laboratory of Quality Research in Chinese Medicines, Macau Institute for Applied Research \\ in Medicine and Health, Macau University of Science and Technology, Taipa, Macau SAR 000853; \\ ${ }^{2}$ Nursing Department, The Affiliated Hospital of Southwest Medical University; \\ ${ }^{3}$ Immunology Department, The School of Basic Medical Sciences, \\ Southwest Medical University, Luzhou, Sichuan 646000, P.R. China
}

Received April 1, 2019; Accepted September 25, 2019

DOI: $10.3892 / \mathrm{mmr} .2019 .10880$

\begin{abstract}
Thymic stromal lymphopoietin (TSLP) is a potentially important target for the treatment of asthma and malignancies. However, a fully human antibody reactive with TSLP is currently unavailable for clinical use. In a previous study, a human anti-TSLP-single-chain antibody variable fragment (anti-TSLP-scFv) 84 was selected by phage display from a constructed human scFv library. In the present study, a computer simulation method was developed using Discovery Studio 4.5 software, to increase the affinity of anti-TSLP-scFv-84. Specific primers were designed and mutated DNA sequences of anti-TSLP-scFvs were obtained by overlap extension PCR. The mutant scFvs were expressed in pLZ16 and affinity-enhanced anti-TSLP-scFv-M4 was screened using ELISA. However, in general the scFvs have low stability and short half-lives in vivo. Therefore, scFv-84 and scFv-M4 were inserted into eukaryotic expression vectors (pcDNA3.1-sp-Fc and PMH3 $3^{\mathrm{EN}}$-sp-Fc) and then transfected into $293 \mathrm{~F}$ cells to express anti-TSLP-scFv-Fc. ELISA and western blotting results indicated the size of the anti-TSLP-scFV-Fc to be $\sim 50 \mathrm{kDa}$. Binding of anti-TSLP-scFv-Fc-M4 to TSLP was enhanced compared with the pre-mutated scFv-Fc-84. The affinity of the mutated recombinant antibody was determined using the BIAcore technique and found to be $\sim 10$-fold greater than the pre-mutated antibody.
\end{abstract}

Correspondence to: Professor Qing Yuan, Immunology Department, The School of Basic Medical Sciences, Southwest Medical University, 319 Zhongshan Road, Jiangyang, Luzhou, Sichuan 646000, P.R. China E-mail: qingyuan@swmu.edu.cn

*Contributed equally

Key words: thymic stromal lymphopoietin, affinity improvement, recombinant antibody, molecular docking

\section{Introduction}

Thymic stromal lymphopoietin (TSLP) is a cytokine secreted by airway epithelium that was first identified from thymic stromal cells by Friend et al in 1994 (1). TSLP is known to be involved in the initiation of an inflammatory cascade and has been shown to be upregulated in a variety of clinical conditions, including atopic dermatitis, allergic asthma, inflammatory bowel disease, breast cancer, cervical cancer and lung cancer $(2,3)$. Recently, Kuan and Ziegler (4) demonstrated that the antibody blockade of TSLP significantly inhibited the growth, and lung metastasis of breast cancer in a model system. These observations suggest a potential role for TSLP in human disease and further suggest that antibody disruption of TSLP and the TSLP receptor (TSLPR) signalling pathways may have clinical benefit for diseases that lack effective treatment. However, a fully human antibody reactive with TSLP is currently unavailable for clinical use.

Engineered antibodies have many advantages over murine monoclonal antibodies, including that they are not murine, and can be modified at the genetic and molecular levels to meet requirements for immunogenicity, stability and specificity in vivo (5). However, engineered antibodies obtained by antibody library screening have not undergone affinity maturation in vivo and their affinity is generally not acceptable for clinical use (6). Therefore, affinity maturation of recombinant antibodies in vitro is required. Traditional strategies for the modification of engineered antibodies are random, labour intensive and time consuming. In the present study, Discovery Studio (DS) 4.5 software was used for homology modelling of antibodies, antigens and predicted molecular anomalies in amino acid residues. With this software, molecular dynamic simulation and site-directed mutagenesis can be performed for in vitro affinity maturation of a recombinant anti-TSLP single-chain antibody variable fragment (anti-TSLP-scFv). The software is simple to operate, easy to use, low in cost and is not time or labour intensive. The fully human recombinant immunoglobulin (anti-TSLP-scFv-Fc-M4) obtained using the DS 4.5 software was $\sim 50 \mathrm{kDa}$ and its affinity was increased 10 -fold. 


\section{Materials and methods}

Virtual mutation of amino acids of anti-TSLP-scFv-84 TSLP homology modelling. The TSLP amino acid sequence was uploaded into the DS 4.5 platform (NeoTrident Technology Ltd.). The template (NCBI Gene ID: 85450) was selected from gene sequences with the highest homology, performed using the Basic Local Alignment Search Tool (BLAST). Energy minimizations were performed as described by the TSLP antigen homology modelling method $(7,8)$. The rationality of the model was evaluated using a Ramachandran plot and the Profile-3D program using DS software.

Anti-TSLP-scFv-84 homology modelling. A diverse and natural full-human scFvs antibody library, with a capacity of $2.5 \times 10^{8}$, was constructed using mRNA of PBMC from healthy volunteer in a previous study (9). By phage display, biotinylated TSLP protein was used as an antigen to select human anti-TSLP-scFv from the constructed human scFv library following the protocol previously described (9). The selected anti-TSLP-scFv-84 amino acid sequence was uploaded into the DS 4.5 system. Antibody domain and complementarity determining region (CDR) sequences were identified and annotated using the Annotate Antibody Sequence protocol (Discovery studio visualizer version 16.1.0.15350) (10). The sequences of variable heavy chain $(\mathrm{VH})$ and variable light chain (VL) were set according to similarity, surface, light and heavy chain templates, resulting in the greatest degree of sequence similarity. The optimal model V_H_V_L_M0004_M was selected using probability density function (PDF) total energy, PDF physical energy and discrete optimized protein energy (DOPE) Score. Finally, a three-dimensional model of anti-TSLP-scFv-84 was constructed and the rationality of the model evaluated using Profile-3D and a Ramachandran plot.

Antibody-antigen docking. Optimized anti-TSLP-scFv-84 as a receptor and TSLP as a ligand, with docked poses and clusters, were obtained using the ZDOCK operation (Discovery studio visualizer v16.1.0.15350). Scanning alanine and saturation mutations in the docking region were used to predict amino acid mutation sites for increased affinity. Based on mutational energy, amino acid sites were selected to increase the affinity of the antibody after mutation.

Screening and verification of anti-TSLP-scFv mutations. Overlap extension PCR. Based on DS system predictive mutation sites (Table SI), single-point mutation primers were designed (Table SII) and synthetized by Invitrogen, Thermo Fisher Scientific, Inc. Using the method of overlap extension PCR, the recombinant plasmid anti-TSLP-scFv-84 (pre-mutated) served as the PCR template in the two first stage reactions. The first and second PCR amplifications were performed using 32 cycles at $98^{\circ} \mathrm{C}$ for $10 \mathrm{sec}, 60^{\circ} \mathrm{C}$ for $30 \mathrm{sec}$ and $72^{\circ} \mathrm{C}$ for $1 \mathrm{~min}$; The first and second PCR products were mixed as templates for the third PCR. The third PCR amplification was performed 10 cycles at $98^{\circ} \mathrm{C}$ for $10 \mathrm{sec}, 60^{\circ} \mathrm{C}$ for $30 \mathrm{sec}$ and $72^{\circ} \mathrm{C}$ for $1 \mathrm{~min}$; Then, Forward primer scFv84F-TSLP and reverse primer KM168 were added for 20 cycles. Finally, single point mutations products of anti-TSLP-scFv were obtained (M1, M2, M3, M4 and M5). The amplified PCR products was electrophoresed on a $1.5 \%$ agarose gel in $1 \mathrm{X}$ Tris borate EDTA buffer with $\mathrm{pH} 8.3$ and $0.03 \mu$ l ethidium bromide. The gel was visualized under ultraviolet light.

Screening of mutated anti-TSLP-scFvs in the prokaryotic expression vector pLZ16. A TSLP-pLZ16 plasmid was constructed in our previous study based on the pUC vector (11). The mutated anti-scFv fragment and the pLZ16 vector were digested with $\operatorname{Not} \mathrm{I}$ and $N o c \mathrm{I}$ restriction enzymes at $37^{\circ} \mathrm{C}$ for $4 \mathrm{~h}$. The products were ligated using $1 \mu \mathrm{l} \mathrm{T} 4$ ligase (Takara Bio, Inc.) at $16^{\circ} \mathrm{C}$ for $12 \mathrm{~h}$ and transformed into $D H 5 \alpha F^{\prime}$ competent cells (Tiangen Biotech Co., Ltd.). Transformed positive scFvs were identified by PCR using 30 cycles at $98^{\circ} \mathrm{C}$ for $10 \mathrm{sec}, 55^{\circ} \mathrm{C}$ for $30 \mathrm{sec}$ and $72^{\circ} \mathrm{C}$ for $1 \mathrm{~min}$. High-fidelity thermostable ExTaq enzyme (Takara Biotechnology Co., Ltd.) and forward primer scfv84F-TSLP: 5'-CATGCCATGGCCGGCCCAGCCGGC CC-3', reverse primer KM168: 5'-CTGAGTAGAAGAACT CAAACTA-3' were employed. The positive scFvs clones were cultured on a shaker at $37^{\circ} \mathrm{C}, 200 \mathrm{rpm}$ for overnight, and the plasmids were extracted with QuickPure Plasmid Mini Kit (CW Biotech) and Sanger sequenced by Shanghai Sangon Biotech Co., Ltd. The sequences were aligned in BLAST (Fig. S1). The pre-mutation scFv84 and mutant scFvs (M1, M2, M4 and M5) were expressed at a constant temperature of $32^{\circ} \mathrm{C}$ for $5 \mathrm{~h}$ with $1 \mathrm{mmol} / 1$ lisopropyl $\beta$-D-1-thiogalactopyranoside induction. The expressed scFvs were assessed for binding to human TSLP using indirect ELISA with $200 \mathrm{ng} / \mathrm{ml}$ HRP-labelled anti-FLAG monoclonal antibody (Thermo Fisher Scientific, Inc.) as secondary antibody.

Construction of anti-TSLP-ScFv-Fc eukaryotic expression vectors

Construction of pcDNA3.1-scFv-Fc expression vectors. The scFv-84 (pre-mutated) and scFv-M4 (mutated) sequences in pLZ16 were amplified by PCR with scFv84-KpnI-F (5'-CGG GGT ACCATGGCCGGCCCAGCCGGCCCA-3') and scFv84-BamHI-R-C (5'-CGCGGATCCACGTTTGATCTC CAGCTTGGTCC-3') (12). PCR amplifications were performed with ExTaq enzyme, using 30 cycles at $98^{\circ} \mathrm{C}$ for $10 \mathrm{sec}, 55^{\circ} \mathrm{C}$ for $30 \mathrm{sec}$ and $72^{\circ} \mathrm{C}$ for $1 \mathrm{~min}$. The target DNA fragment was digested with $\mathrm{KpnI}$ at $37^{\circ} \mathrm{C}$ for $4 \mathrm{~h}$ and $\mathrm{BamHI}$ at $30^{\circ} \mathrm{C}$ for $4 \mathrm{~h}$, and then ligated with $\mathrm{T} 4$ ligase at $16^{\circ} \mathrm{C}$ for $12 \mathrm{~h}$ into pcDNA3.1-sp-Fc [constructed in previous work (12), sp and IgG1 Fc were insert into pcDNA3.1] to generate the pcDNA3.1-sp-scFv-Fc recombinant vectors. There combinant vectors were transformed into E. coli TOPO10 competent cells (Takara Bio, Inc.). Positive clones with the correct sp-scFv-Fc were identified by PCR using 30 cycles at $98^{\circ} \mathrm{C}$ for $10 \mathrm{sec}, 55^{\circ} \mathrm{C}$ for $30 \mathrm{sec}$ and $72^{\circ} \mathrm{C}$ for $90 \mathrm{sec}$ with ExTaq enzyme (Takara Bio, Inc.). The constructed plasmids were sequenced by Shanghai Sangon Biotech Co., Ltd.

Construction of $P M H 3^{E N}-s c F v-F c$ expression vectors. The sp-scFv-Fc-84 (Pre-mutated) and sp-scFv-Fc-M4 (mutated) in pcDNA3.1 were amplified by PCR using 30 cycles at $98^{\circ} \mathrm{C}$ for $10 \mathrm{sec}, 55^{\circ} \mathrm{C}$ for $30 \mathrm{sec}$ and $72^{\circ} \mathrm{C}$ for $90 \mathrm{sec}$ with ExTaq enzyme (Takara Bio, Inc.) (11). Forward primers pcDNA3.1-F (5'-CTAGAGAACCCACTGCTTAC-3') and pcDNA3.1-R (5'-TAGAAGGCACAGTCGAGG-3') were employed. The target DNA fragment was digested with HindIII and NotI at $37^{\circ} \mathrm{C}$ for $4 \mathrm{~h}$, and then ligated with $\mathrm{T} 4$ ligase $\left(16^{\circ} \mathrm{C}, 12 \mathrm{~h}\right)$ to 
$\mathrm{PMH}^{\mathrm{EN}}$ (Hangzhou Amprotein BioEngineering Co., Ltd.) to generate the $\mathrm{PMH} 3^{\mathrm{EN}}$-sp-scFv-Fc recombinant vectors. There combinant vectors were transformed and positive clones were identified as afore mentioned.

\section{Verification of anti-TSLP-ScFv-Fc affinity}

Cell preparation and transient transfection. Transformed 293F cells were obtained from Abace Biotechnology Co., Ltd. and maintained in serum-free FreeStyle ${ }^{\mathrm{TM}} 293$ expression medium (Gibco; Thermo Fisher Scientific, Inc.). Cells were cultured as described previously $(13,14)$. Filter-sterilized plasmid DNA (PMH3 ${ }^{\mathrm{EN}}$, $\mathrm{PMH}^{\mathrm{EN}}{ }_{\text {-sp-scFv-Fc-84/M4 vector) }}$ was prepared for transfection as described previously (14). Briefly, $293 \mathrm{~F}$ cells were cultured at $1 \times 10^{6}$ cells $/ \mathrm{ml}$ to a final volume of $90 \mathrm{ml}$ with Serum-free Freestyle ${ }^{\mathrm{TM}} 293$ expression medium in roller bottle (Corning). Filter-sterilized DNA $(100 \mu \mathrm{g})$ was added to $10 \mathrm{ml}$ of 1 XPBS and vortexed for $5 \mathrm{sec}$. Then, $313 \mu l$ of $1 \mathrm{mg} / \mathrm{ml}$ filter-sterilized polyethylenimine PEI (Polysciences, Inc.) solution was pipetted into the DNA/PBS mixture. The DNA/PEI/PBS mixture was added to the cells, which were incubated in an orbital shaker incubator at $37^{\circ} \mathrm{C}$, $120 \mathrm{rpm}$ and $8 \% \mathrm{CO}_{2}$ for $72 \mathrm{~h}$. After centrifuging at $4^{\circ} \mathrm{C}, 350 \mathrm{~g}$ for $10 \mathrm{~min}$, the cells pellet was collected and stored at $-80^{\circ} \mathrm{C}$ for ELISA and western blotting.

Direct ELISA. After centrifuging, cells were resuspended in 1XPBS buffer and sonicated. The sonicated cell solutions were centrifuged and the supernatant containing the expressed protein was used to ELISA. scFv-Fc-84/M4 protein solutions were dilute with 1XPBS (at various concentrations 1:1, 1:10, 1:100, 1:1,000 and 1:10,000) derived from the $\mathrm{PMH}^{\mathrm{EN}}$ vector were used to coat 96 -well plates overnight at $4^{\circ} \mathrm{C}$ in $50 \mathrm{mM}$ $\mathrm{NaHCO}_{3} / \mathrm{Na}_{2} \mathrm{CO}_{3}$ (pH 9.6). $200 \mathrm{ng} / \mathrm{ml}$ goat $\mathrm{pAb}$ to $\mathrm{Hu} \mathrm{IgG}$ (HRP) (Abcam, ab97225) was used to detect PMH3 $3^{\mathrm{EN}}$-scFv-Fc as described previously (15). The absorbance of each well was detected at $450 \mathrm{~nm}$.

Indirect ELISA. As described previously (9), $10 \mu \mathrm{g} / \mathrm{ml}$ TSLP (Sino Biological Inc.) was coated in 96-well plates overnight at $4^{\circ} \mathrm{C}$. Following this, a scFv-Fc-84/M4 protein solution $(1: 1,1: 10,1: 100,1: 1,000,1: 10,000)$ expressed in PMH3 ${ }^{\text {EN }}$ was added to the plates, then $200 \mathrm{ng} / \mathrm{ml}$ goat pAb to $\mathrm{Hu} \mathrm{IgG}$ (HRP, 1:5,000; Abcam, ab97225) was added to measure binding between antigen TSLP (Sino Biological) and antibody $\mathrm{PMH}^{\mathrm{EN}}$-scFv-Fc-84/M4. The absorbance of each well was detected at $450 \mathrm{~nm}$.

Western blotting. The scFv-Fc-84/M4 protein solutions were prepared by sonicating the transfected $293 \mathrm{~F}$ cells in $1 \mathrm{xPBS}$ as afore mentioned and the BCA method was used to determine the protein concentration. Total cellular proteins [30 $\mu \mathrm{g}$ : Control (cells only), $\left.\mathrm{PMH}^{\mathrm{EN}}, \mathrm{scFv}-\mathrm{Fc}-84 / \mathrm{M} 4\right]$ expressed in the PMH3 ${ }^{\mathrm{EN}}$ were subjected to SDS-PAGE with $10 \%$ gels and transferred to nitrocellulose membranes. After blocking with 5\% non-fat milk for $1 \mathrm{~h}$ at room temperature, the membranes were incubated with $200 \mathrm{ng} / \mathrm{ml}$ goat pAb to Hu IgG (HRP, 1:5,000; Abcam, ab97225) for overnight at $4^{\circ} \mathrm{C}$. A chemiluminescence detection kit (GE Healthcare) was used to detect the expression of $\mathrm{scFv}-\mathrm{Fc}-84 / \mathrm{M} 4$. According to previously described methods (16), $5 \mu \mathrm{g}$ TSLP
(16135-H08H; Sino Biological, Inc.) was subjected to electrophoresis and membranes were subsequently incubated with scFv-Fc-84/M4 $(400 \mathrm{ng} / \mathrm{ml})$ antibodies overnight at $4^{\circ} \mathrm{C}$, a secondary anti-human IgG Fc HRP-conjugated antibody was used to detect the binding ability of antigen (TSLP) and antibody (scFv-Fc-84/M4).

Affinity test. The $\mathrm{scFv}-\mathrm{Fc}-84 / \mathrm{M} 4$ protein solutions were prepared as afore mentioned. In total, $4 \mu \mathrm{l}$ protein supernatant of the single-chain antibody scFv-Fc-84/M4 was coupled to a protein A biosensor (Pall ForteBio). Subsequently, $4 \mu 1$ standard recombinant human ( $\mathrm{rHu})$ TSLP protein $(5,10$ and $20 \mathrm{nM}$; Sino Biological Inc.) was used to assess sensor interaction. By systematically analysing antigen-antibody binding and dissociation, affinity dissociation constant (KD) values were calculated. The interaction between antigen (TSLP) and antibody (anti-TSLP-scFv-Fc) were analyzed by Octet RED96 (Pall ForteBio). Acquired data were analyzed by the custom ForteBio software Data Acquisition 9.0.

Statistical analysis. All experiments were repeated three times. Data are expressed as the mean \pm SEM. One-way ANOVA and Tukey's Multiple Comparison Test were used to determine significance with GraphPad Prism 5 software (GraphPad Software, Inc.). P $<0.05$ was considered to indicate a statistically significant difference.

\section{Results}

Virtual mutation of amino acids of anti-TSLP-scFv Establishment and evaluation of the TSLP homologous model. After aligning the TSLP protein sequence (NCBI Gene ID: 85450) with the NCBI crystal library sequence, the DS 4.5 software package was used to detect the template gene sequence with the highest homology. With homology constraints, 20 optimized models were obtained. TSLP. M0020 (Fig. 1A) exhibited the lowest PDF total energy; this model was evaluated using a Ramachandran plot (Fig. 1B). The blue region indicates the optimal zone. The more amino acids (indicated by green circles) in the optimal region, the more reliable the structure. The purple region indicates the permitted zone. The pink circles are amino acids with $\psi-\phi$ conformations that are unreasonable; these regions require optimization. A Profile-3D score $>0.0$ indicated that the amino acids were compatible (Fig. 1C).

Establishment and evaluation of the anti-TSLP-scFv-84 homologous model. The DS system predicted domains and CDRs of the anti-TSLP-scFv-84 antibody. In total, 25 templates were obtained as 'identify framework templates'. 4P59 LH was selected as the overall template, 4HS6 A as the light chain template and 4KFZ $\mathrm{C}$ as the heavy chain template. The model antibody framework protocol and the model antibody loops protocol simulated models of the $\mathrm{scFv}$ framework region and CDR. Finally, V_H_V_L_M0004_M. M0002 was selected as the best 3D model through PDF total energy, PDF physical energy and DOPE Score (Fig. 2A). This reasonable model was evaluated using a Ramachandran plot; nearly all amino acids were within the optimal zone (blue area). Only a few amino acids required optimization within the permitted region (pink 

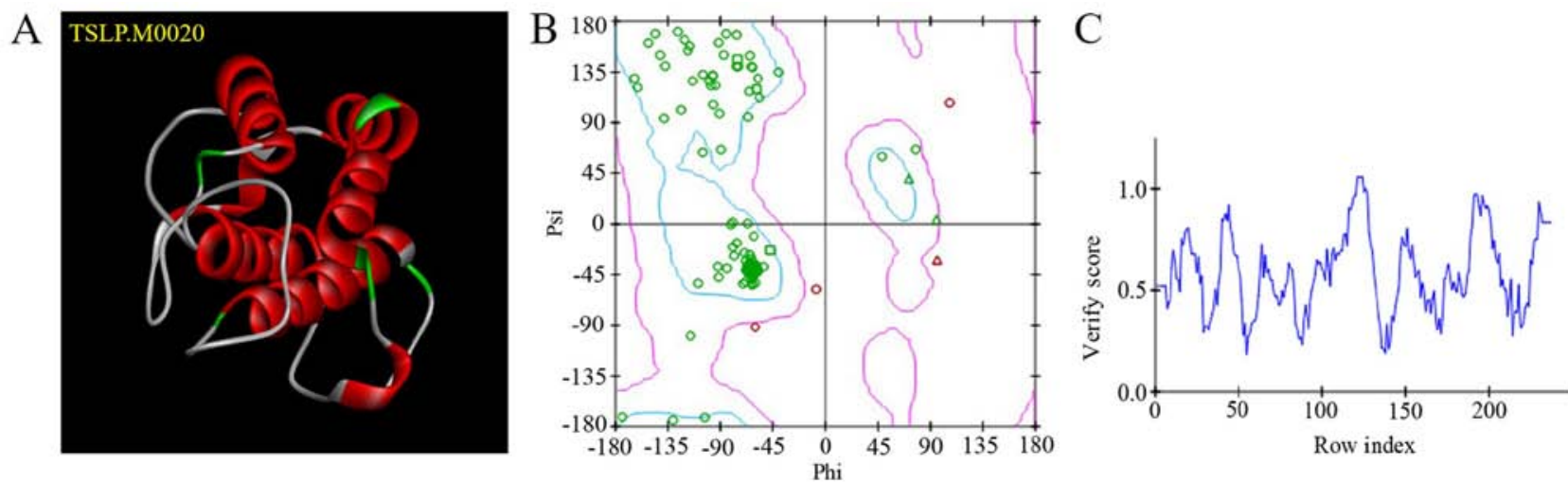

Figure 1. Homology modelling of TSLP. (A) Three-dimensional structure of TSLP. (B) Ramachandran plots of the structure of TSLP. The blue region indicates the optimal zone and the purple region indicates the permitted zone. Green circles indicate amino acids in the optimal zone; pink circles indicate amino acids in the permitted region. (C) Profile-3D verification of TSLP. A score $>0.0$ indicates that the amino acids are compatible. TSLP, thymic stromal lymphopoietin.
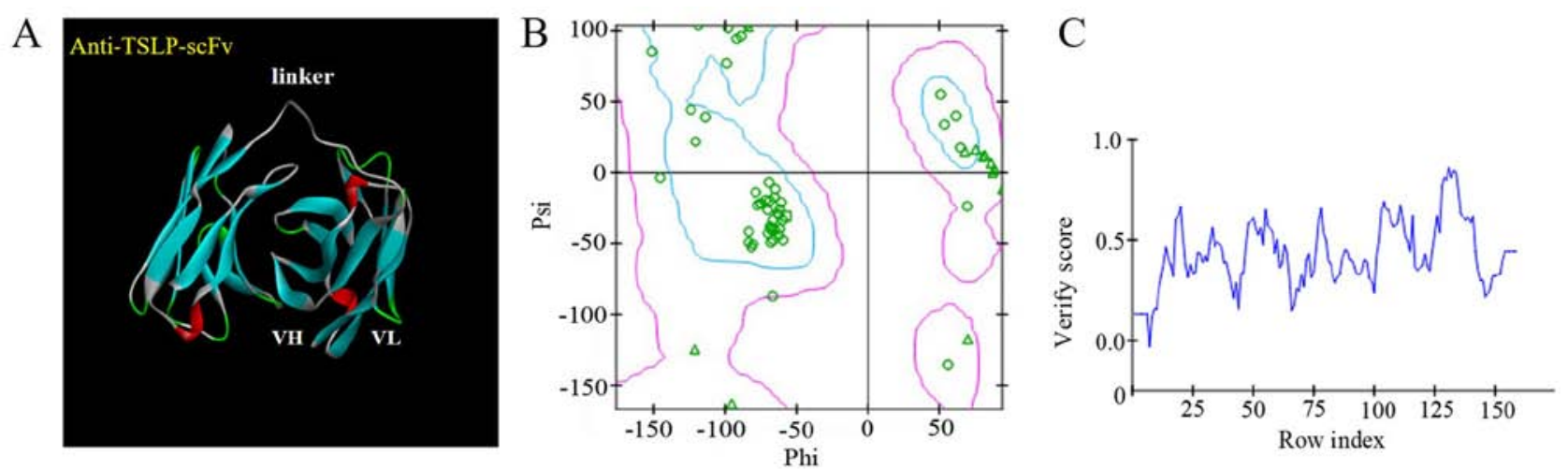

Figure 2. Homology modelling of anti-TSLP-scFv-84. (A) Three-dimensional structure of anti-TSLP-scFv-84. (B) Ramachandran plots of anti-TSLP-scFv-84 structure. The blue region indicates the optimal zone and the purple region indicates the permitted zone. Green circles indicate amino acids in the optimal zone. (C) Profile-3D verification of anti-TSLP-scFv-84. A score $>0.0$ indicates that the amino acids are compatible. scFv, single-chain antibody variable fragment; TSLP, thymic stromal lymphopoietin; VH, variable heavy chain; VL, variable light chain.

area; Fig. 2B).A Profile-3D score $>0.0$ indicated that the amino acids were compatible (Fig. 2C).

Antibody-antigen docking and virtual mutation. Anti-TSLP-scFv-84 as the receptor and TSLP as the ligand were docked with docking proteins. Refine docked protein optimization was performed based on CHARMm force field energy. The range of root mean square deviation of POSE50 was $0.2-1.0 \mathrm{~A}$ as measured by molecular dynamics. This result indicated that the dynamic change of the model in solution was reasonable (Fig. 3A). The binding regions of TSLP and anti-TSLP-scFv-84 were analyzed using the DS system and the CDRs were mutated. In total, five key amino acid residues that could increase antibody affinity after mutation were predicted by alanine scanning. The five amino acid combinations were as follows: TRP (109)-ARG, TRP (109)-LYS, TRP (109)-TYR, TRP (109)-LEU, TRP (109)-GLU (Table SI; Fig. 3B; 109 is the number of amino acid in the variable region), with the largest negative energy value $(<-4)$ identified by saturation mutagenesis and mutation energy (Fig. 3C).

Screening and verification of anti-TSLP-scFv mutations Single point mutations of anti-TSLP-SCFv assessed by PCR. The pre-mutated and DS system-predicted mutated amino acids of scFv M1, M2, M3, M4 and M5 are presented in Table SI. Primers were designed based on the predicted mutation sites (Table SII) and paired to amplify the pre- and post-fragments of the mutation sites. The fragments were connected by overlap extension PCR. The products were $750 \mathrm{bp}$, which demonstrated that the fragments were connected successfully (Fig. 4A and B).

Screening of mutated anti-TSLP-scFv by expression in $\mathrm{pLZ16}$, a prokaryotic expression vector. $\mathrm{scFv}$ M1, M2, M3, M4 and M5 were inserted into the pLZ16 prokaryotic expression vector. The sequencing results demonstrated that the amino acids in M1, M2, M4 and M5 were mutated successfully; however, scFv-M3 had a stop codon (data not shown). Therefore, scFv M1, M2, M4 and M5 were expressed in the pLZ16 prokaryotic expression vector. The target protein was detected using HRP-labelled anti-FLAG monoclonal antibody. Indirect ELISA results demonstrated that mutated scFv-M4 exhibited significantly increased binding to antigen compared with the pre-mutant scFv-84 (Fig. 4C). The expression of scFv-84/M4 was detected by coating the wells of a 96-well plate with the expressed single-chain antibody. The results revealed that the expression of $\mathrm{scFv}-84$ was significantly higher than M4 (Fig. 4D). However, when combined with the antigen, scFv-84 

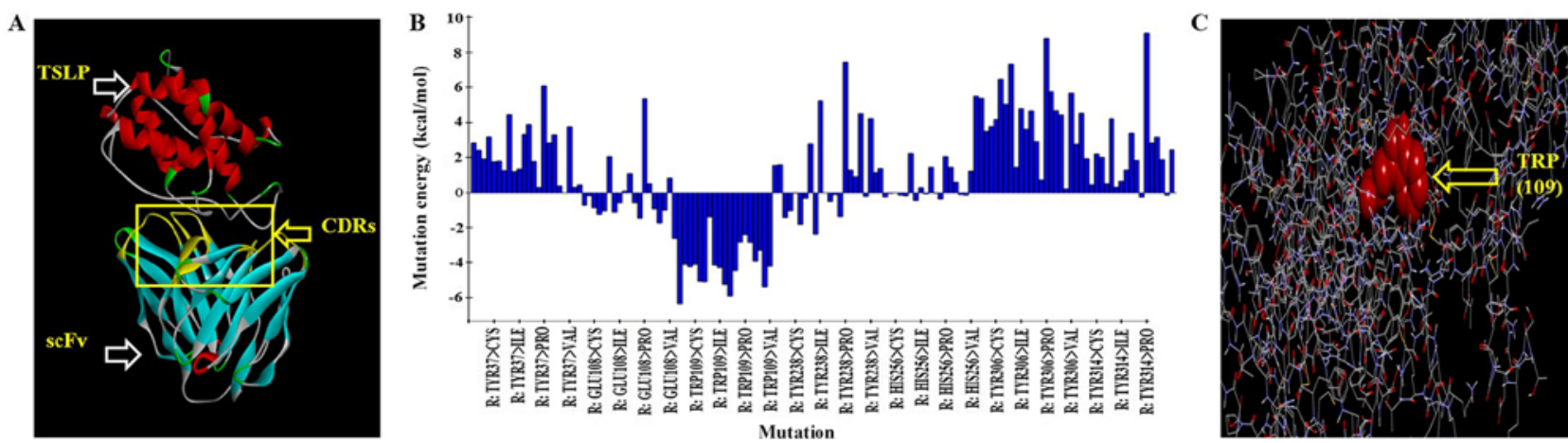

Figure 3. Analysis of the antigen-antibody binding surface and virtual mutation of the key amino acid of anti-TSLP-scFv-84. (A) Molecular docking and molecular dynamic simulation of TSLP and anti-TSLP-scFv. (B) Mutation energy of key amino acids of the scFv. (C) Virtual mutation of the key amino acid of scFv. CDR, complementarity determining region; $\mathrm{scFv}$, single-chain antibody variable fragment; TSLP, thymic stromal lymphopoietin.
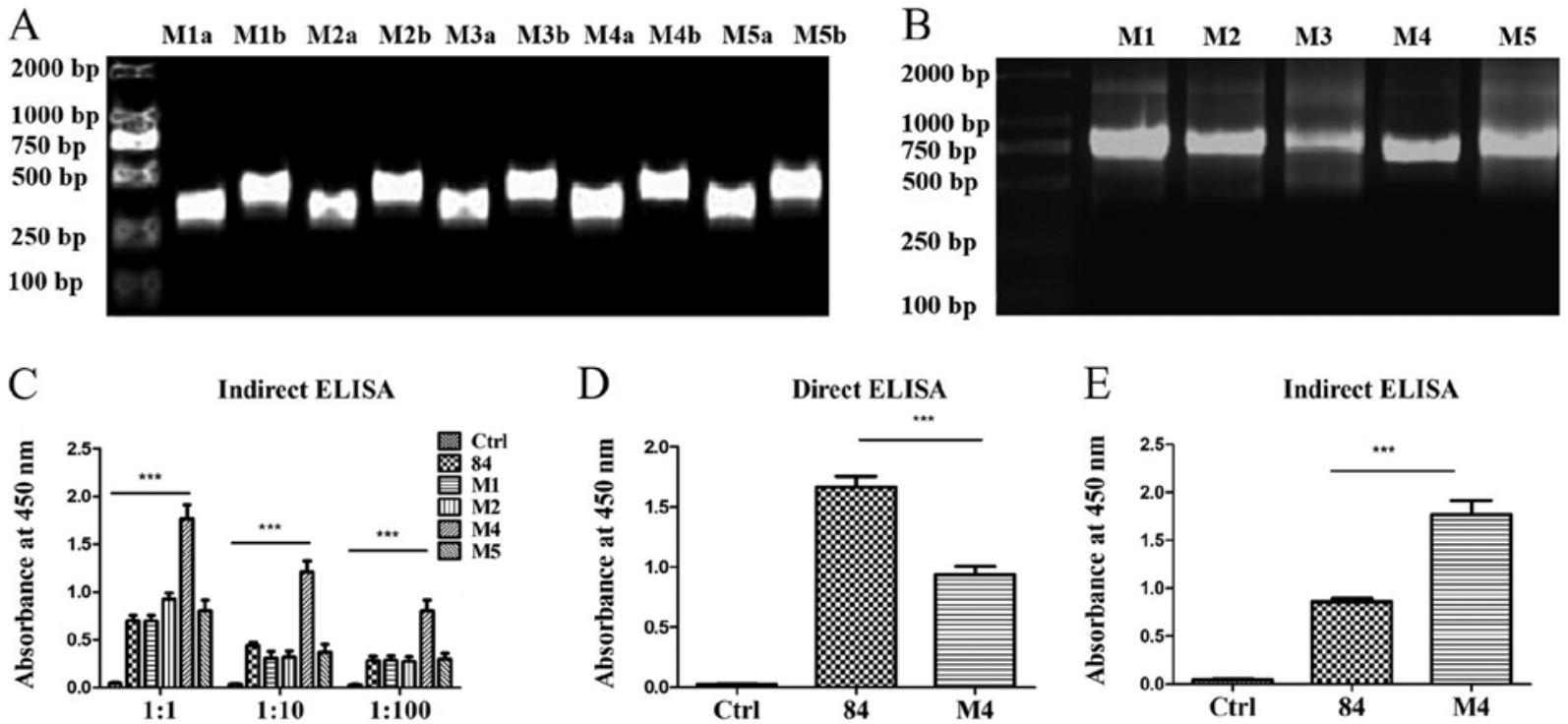

Figure 4. Amplification of mutated scFv by PCR and detection of scFvs binding to TSLP by ELISA. (A) PCR amplification of (a) the 5' end of the coding sequences and (b) the $3^{\prime}$ end of the coding sequences containing the mutated amino acids of the scFv 84 separately. (B) Joining of the 5' end of the coding sequences and $3^{\prime}$ end of the coding sequences containing the mutated amino acids using overlap extension PCR. (C) Indirect ELISA was used to detect the binding of scFvs with TSLP by coating the wells of ELISA plates with the TSLP antigen. 84 refers to the sequence prior to mutation, M1, M2, M4 and M5 refer to sequences following mutation. (D) ELISA detection of the expression levels of pre-mutated scFv-84 and mutated scFv-M4. (E) Indirect ELISA for the detection of the binding of pre-mutated scFv-84 and mutated scFv-M4 to TSLP. ${ }^{* * *} \mathrm{P}<0.001$. scFv, single-chain antibody variable fragment; TSLP, thymic stromal lymphopoietin.

binding was significantly lower than that of M4 (Fig. 4E), indicating enhanced affinity for mutated M4.

\section{Construction of the anti-TSLP-scFv-Fc eukaryotic expression} vector

Construction of the pcDNA3.1-sp-scFv-Fc expression vector. In general, $\mathrm{scFv}$ have a low stability, low affinity and a short half-life in vivo (5). Therefore, the pre-mutated $\mathrm{scFv}-84$ and affinity enhanced scFv-M4 genes were inserted into the eukaryotic expression vector pcDNA3.1-sp-Fc. The vectors were transfected into $293 \mathrm{~F}$ cells to express the IgG-like anti-TSLP-scFv-Fc fusion protein. Based on the cloning site for the pcDNA3.1-sp-Fc vector, specific primers were designed and the scFv gene fragment of the single-chain antibody was amplified using the ExTaq enzyme. A single band of $750 \mathrm{bp}$ was detected by agarose gel electrophoresis of the PCR product that contained scFv (Fig. S2A). After digestion with KpnI and BamHI, anti-TSLP-scFv was ligated into the pcDNA3.1-sp-Fc vector with T4 ligase. The results demonstrated that $\mathrm{scFv}-84$ and $\mathrm{scFv}-\mathrm{M} 4$ were recombined with pcDNA3.1-sp-Fc successfully (Fig. S2B).

Construction of the PMH3 ${ }^{E N}-s p-s c F v-F c$ expression vector. As the expression level of scFv-Fc in pcDNA3.1 was low (Fig. 5A and B), the recombinant plasmid PMH3 ${ }^{\mathrm{EN}}$ was used to improve expression. The pcDNA3.1 vector was digested with HindIII and NotI. Expression of sp-scFv-Fc-84/M4 was detected by agarose gel electrophoresis (Fig. S3A). Specific primers were designed based on the cloning site of the $\mathrm{PMH} 3^{\mathrm{EN}}$ vector and the anti-TSLP-scFv-Fc sequence. Empty plasmid $\mathrm{PMH}^{\mathrm{EN}}$ was cleaved with HindIII and NotI. Then sp-scFv-Fc was ligated into the PMH3 ${ }^{\mathrm{EN}}$ vector (Fig. S3B). Sequencing results demonstrated that the full-length $\mathrm{sp}-\mathrm{scFV}-\mathrm{Fc}$ had been inserted into all clones. 
A

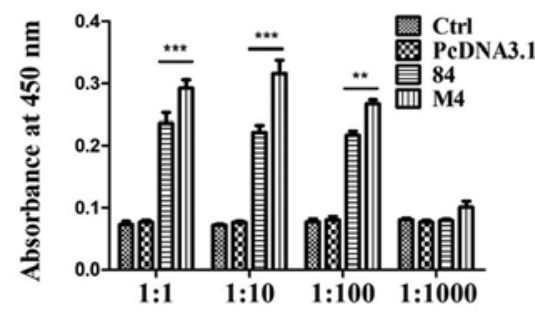

B

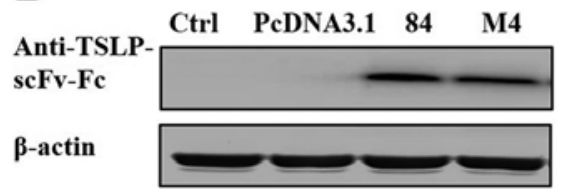

C

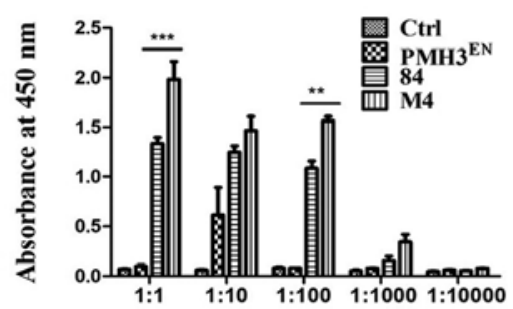

D

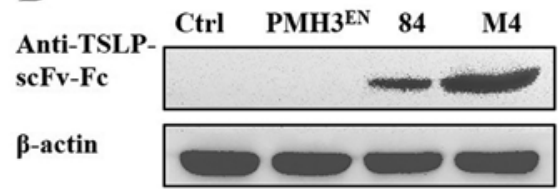

E

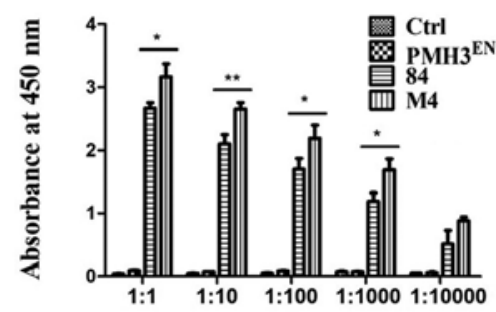

F

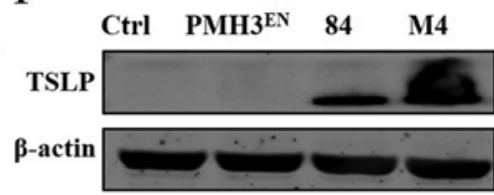

Figure 5. Detection of the expression levels of scFv-Fc in pcDNA3.1 and PMH3EN vectors, and detection of the binding ability between TSLP and scFv-Fcs by ELISA and western blotting. (A) Expression levels of scFv-Fc-84/M4 in pcDNA3.1 were detected by direct ELISA. (B) Expression levels of scFv-Fc-84/M4 in pcDNA3.1 were detected by western blotting. (C) Expression levels of scFv-Fc-84/M4 in PMH3EN were detected by direct ELISA. (D) Expression levels of scFv-Fc-84/M4 in PMH3EN were detected by western blotting. (E) Binding ability between TSLP and scFv-Fc-84/M4 expressed in PMH3EN was detected by indirect ELISA. (F) Binding ability between TSLP and scFv-Fc-84/M4 expressed in PMH3EN was detected by western blotting. ${ }^{*} \mathrm{P}<0.05,{ }^{* *} \mathrm{P}<0.01,{ }^{* * *} \mathrm{P}<0.001$. Ctrl, control; scFv, single-chain antibody variable fragment; TSLP, thymic stromal lymphopoietin.

Verification of anti-TSLP-scFv-Fc affinity

Expression of anti-TSLP-scFv-Fc antibody. The expression of $\mathrm{PMH}^{\mathrm{EN}}$-scFv-Fc-84/M4 was detected by direct ELISA, which was performed using an anti-TSLP HRP-conjugated antibody. The expression of anti-TSLP-scFv-Fc was not detected from the control and empty plasmid $\mathrm{PMH}^{\mathrm{EN}}$; however, $\mathrm{PMH} 3^{\mathrm{EN}}$-scFv-Fc-84/M4 expression was obvious. Furthermore, expression of $\mathrm{PMH} 3^{\mathrm{EN}}$-scFv-Fc-M4 was significantly higher than $\mathrm{PMH}^{\mathrm{EN}}-\mathrm{scFv}-\mathrm{Fc}-84(\mathrm{P}<0.05$; Fig. 5C). In addition, the expressed anti-TSLP-scFv-Fc protein was identified by western blotting. Using anti-human IgG Fc HRP-conjugated antibody, a single band of $50 \mathrm{kDa}$ was identified (Fig. 5D).

Binding activity of the anti-TSLP-scFv-Fc antibody. Indirect ELISA was used to assess the affinity of the antibody for the antigen. ELISA plates were coated with TSLP and incubated with anti-TSLP-scFv-Fc. An anti-TSLP HRP-conjugated antibody was used to assess the binding of $\mathrm{PMH} 3^{\mathrm{EN}}$-scFv-Fc-84/M4 to TSLP (Fig. 5E). ELISA results indicated that the antibodies bound TSLP and that the binding of PMH3 $3^{\mathrm{EN}}-\mathrm{scFv}-\mathrm{Fc}-\mathrm{M} 4$ was higher than that of $\mathrm{PMH} 3{ }^{\mathrm{EN}}-\mathrm{scFv}-\mathrm{Fc}-84$. Western blotting revealed that the TSLP protein bands specific binding with recombinant $\mathrm{PMH} 3^{\mathrm{EN}}$-scFv-Fc-84/M4 was $\sim 25 \mathrm{kDa}$ (Fig. 5F). A positive association between ELISA and western blotting data confirmed the validity of the results.

Affinity of the anti-TSLP-scFv-Fc antibody. To verify that the affinity of mutated scFv-Fc-M4 was higher after mutation, $\mathrm{PMH}^{\mathrm{EN}}$-scFv-Fc-84/M4 was captured with an anti-Fc biosensor and evaluated with different concentrations of standard rHuTSLP protein. By analysing the process of binding and dissociation (Fig. 6A and B), the affinity KD of PMH3 ${ }^{\mathrm{EN}}$-scFv-Fc-M4 was calculated to be $3.21 \times 10^{-9}$, which was $\sim 10$-fold higher than before the mutation. The product was biologically active and retained high binding affinity to the antigen, as detailed by BIAcore real-time interaction analysis.

\section{Discussion}

A number of previous studies have demonstrated an important role for TSLP in different diseases $(17,18)$. Blocking the binding of TSLP to TSLPR may inhibit TSLP signalling, which may provide a therapeutic strategy to treat various diseases (19). The present study successfully constructed an anti-TSLP-scFv-Fc recombinant antibody. Furthermore, the affinity of the antibody was improved in vitro by homology modelling, molecular docking, virtual mutation and selection of mutation sites. Notably, the affinity of post-mutation anti-TSLP-scFv-Fc increased 10-fold.

With the development of hybridoma technology, mass spectrometry engineering, phage display and transgenic animal technology, the preparation of antibodies has successively transitioned from polyclonal to monoclonal antibodies $(20,21)$. A priority has been the humanization of murine antibodies by genetic engineering, in order to obtain a fully humanized monoclonal antibody with high affinity, stability and biological activity $(22,23)$. Using phage display technology, human ethical issues have been avoided and large numbers of human monoclonal antibodies can be prepared (24). However, these antibodies typically have a low affinity; therefore, in vitro genetic engineering is required to enhance their affinity.

In our previous study, a fully human display library was screened for anti-TSLP-scFv-Fc-84 that had high specificity and the capacity to block the TSLPR in vitro (25). However, single-chain antibodies screened from natural antibody libraries have low affinity and require affinity improvement (5). Random mutation of gene fragments encoding variable regions and directed introduction of mutations are the primary methods for increasing the affinity of recombinant antibodies (26). With the former, mutations are random, unpredictable and time-consuming. However, Lewis et al (27) successfully used alanine scanning to select targeted and random mutations. In the present study, antibody affinity was increased $\sim 10$-fold by replacing one amino acid. Alanine 
A

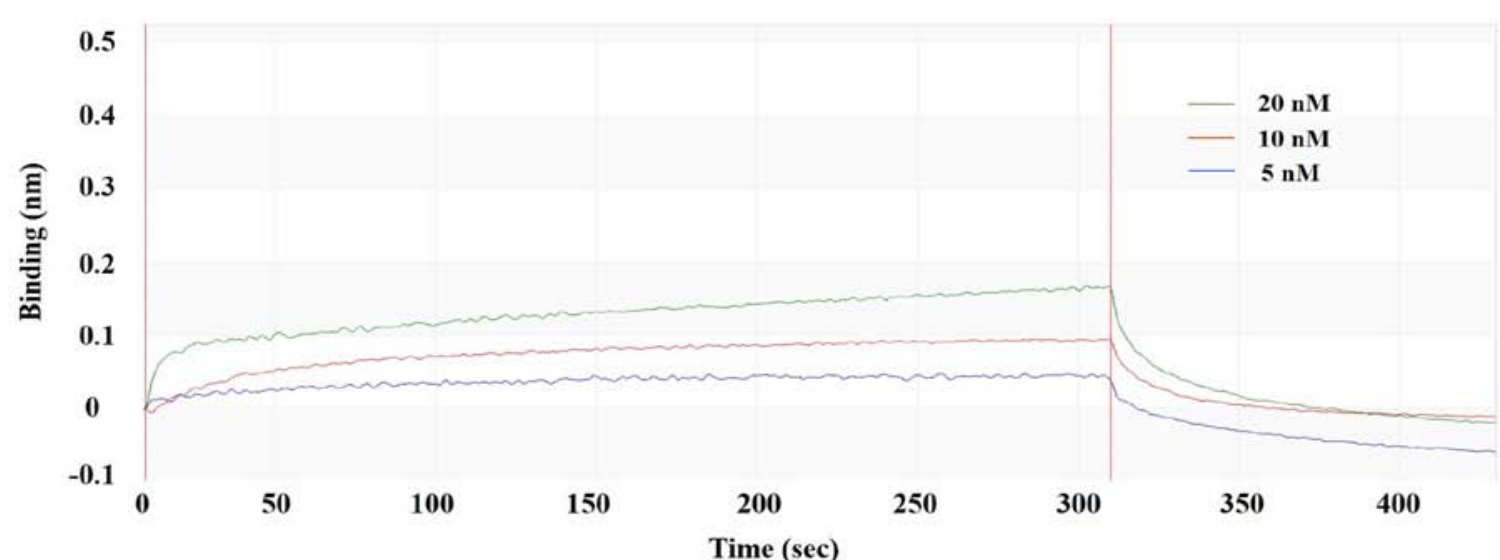

B

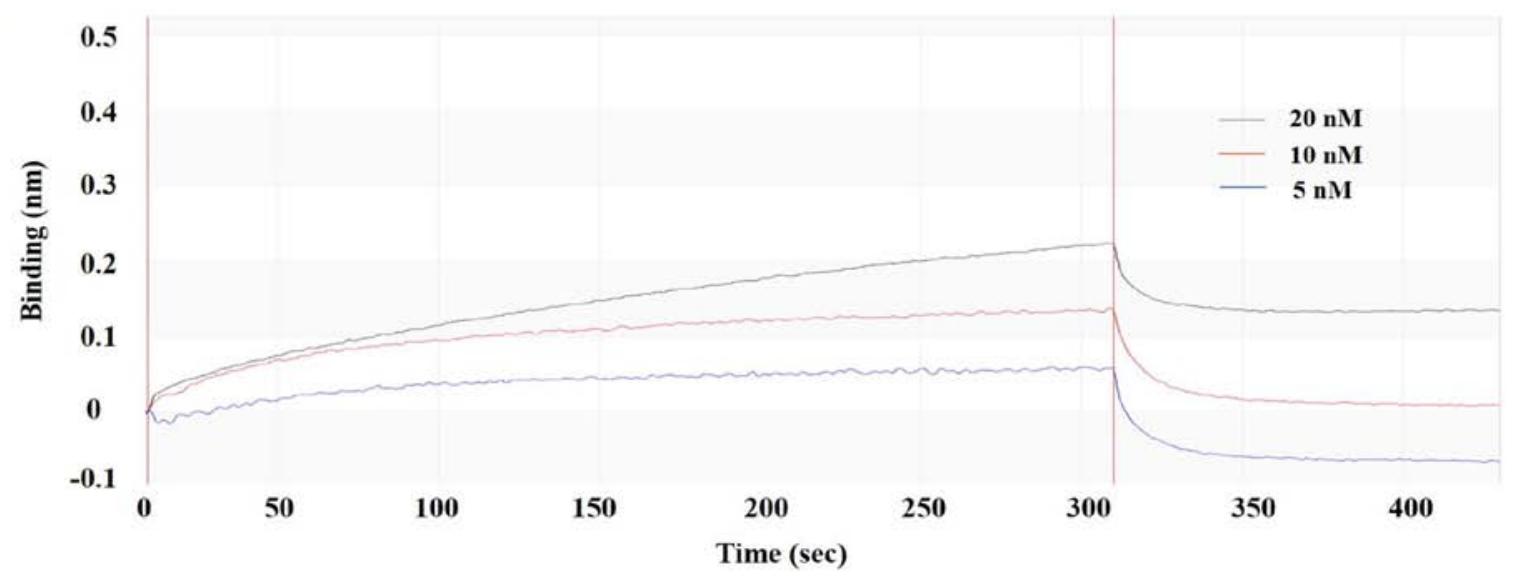

Figure 6. Binding of anti-TSLP-scFv-Fc-84/M4 to rHuTSLP. Anti-TSLP-scFv-Fc-84/M4 was immobilized on a protein A sensor at various concentration $(5,10$ and $20 \mathrm{nM})$ and used to detect binding to the standard rHuTSLP protein. (A) Association and dissociation ofanti-TSLP-scFv-Fc-84 with the rHu TSLP protein. (B) Association and dissociation of anti-TSLP-scFv-Fc-M4 with the rHuTSLP protein. rHu, recombinant human; scFv, single-chain antibody variable fragment; TSLP, thymic stromal lymphopoietin.

scanning mutagenesis was used to identify CDR sites that increased affinity, specificity and stability (28). In the present study, three-dimensional models of TSLP and anti-TSLP-scFv were obtained by homology modelling using the DS 4.5 software. CDR amino acids were then alanine scanned and saturated mutations made to key amino acids. The mutated gene sequence was recombined into the prokaryotic expression vector pLZ16. Mutated M4 was screened using ELISA and found to have an increased affinity for the antigen.

Anti-TSLP-scFv has a short half-life, is easily dimer inactivated, and without an Fc fragment cannot function in antibody-dependent cell-mediated cytotoxicity $(29,30)$. These drawbacks limit applications of anti-TSLP-scFv as a drug for clinical treatment. Moreover, natively folded proteins can be produced by mammalian expression systems; however, they cannot be produced by bacterial expression systems (13). However, 293F cells can be cultured in suspensions and used as a mammalian expression system (31). The polymeric reagent PEI is an inexpensive and highly efficient transfection reagent. PEI can be used to efficiently and quickly transfect $293 \mathrm{~F}$ cells, yielding high levels of recombinant protein (14). Proteins produced by $293 \mathrm{~F}$ cells fold correctly and are biologically active (14). Therefore, the gene sequences of anti-TSLP-scFv (pre-mutated 84 and mutated M4) were cloned into the eukaryotic expression vectors pcDNA3.1-sp-Fc and PMH3 ${ }^{\mathrm{EN}}-\mathrm{sp}-\mathrm{Fc}$.
$293 \mathrm{~F}$ cells were transfected with these vectors and IgG-like recombinant antibodies of anti-TSLP-ScFV-Fc were obtained. The size of anti-TSLP-scFv-Fc, as determined by western blotting, was $\sim 50 \mathrm{kDa}$. The affinity of the antibodies was determined using the BIAcore technique, the affinity of mutated M4 was found to be $\sim 10$-fold higher than the pre-mutated antibody.

At present, there is no anti-TSLP antibody approved by the US Food and Drug Administration (32). As a therapeutic antibody, affinity is the most important characteristic (33). In the present study, an anti-TSLP-scFv-Fc recombinant antibody was successfully constructed and its affinity was increased using DS 4.5 software. This method for improving antibody affinity is stable, efficient and inexpensive.

The present study has some limitations. In our previous study, anti-TSLP-scFvs were derived from a naïve fully human $\mathrm{scFv}$ library. In vitro experiments demonstrated that $\mathrm{scFv}-84$ neutralized TSLP, however, with low affinity. In the present study, the affinity of scFv-84 was enhanced and an scFv-Fc was constructed. In future studies, anti-TSLP-scFv-Fc antibody will be expressed and purified for use in animal models of asthma as a strategy for disease therapy.

In summary, the present study successfully constructed a fully human anti-TSLP-scFv-Fc recombinant antibody of $50 \mathrm{kDa}$. The affinity of mutated anti-TSLP-scFv-Fc-M4 was enhanced 10-fold compared with the pre-mutated antibody. 


\section{Acknowledgements}

Not applicable.

\section{Funding}

The present study was supported by the Science and Technology Department of Luzhou City (grant nos. 2017LZXNYDT06, LY84 and 2018LZXNYD-ZK26), the Innovation Team Project of the Sichuan Education Department (grant no. 16TD0022) and Health Commission of Sichuan Province (grant no. 19PJ291).

\section{Availability of data and materials}

The datasets used and/or analyzed during the current study are available from the corresponding author on reasonable request.

\section{Authors' contributions}

QC performed data analysis and wrote the manuscript. DX and WX performed Discovery Studio software analysis. SN, HY and YW contributed significantly in the interpretation and analysis of the data. QY conceived and designed the study, and revised the manuscript. All authors read and approved the final manuscript.

\section{Ethics approval and consent to participate}

Not applicable.

\section{Patient consent for publication}

Not applicable.

\section{Competing interests}

The authors declare that they have no competing interests.

\section{References}

1. Friend SL, Hosier S, Nelson A, Foxworthe D, Williams DE and Farr A: A thymic stromal cell line supports in vitro development of surface $\operatorname{Ig} \mathrm{M}+\mathrm{B}$ cells and produces a nove growth factor affecting B and T lineage cells. Exp Hematol 22: 321-328, 1994

2. Tatsuno K, Fujiyama T, Yamaguchi H, Waki $M$ and Tokura Y: TSLP directly interacts with skin-homing Th2 cells highly expressing its receptor to enhance IL-4 production in atopic dermatitis. J Invest Dermatol 135: 3017-3024, 2015.

3. Park JH, Jeong DY, Peyrin-Biroulet L, Eisenhut M and Shin JI: Insight into the role of TSLP in inflammatory bowel diseases. Autoimmun Rev 16: 55-63, 2017.

4. Kuan EL and Ziegler SF: A tumor-myeloid cell axis, mediated via the cytokines IL-1 $\alpha$ and TSLP, promotes the progression of breast cancer. Nat Immunol 19: 366-374, 2018.

5. Manoutcharian K, Perez-Garmendia R and Gevorkian G: Recombinant antibody fragments for neurodegenerative diseases. Curr Neuropharmacol 15: 779-788, 2017.

6. Shehata L, Maurer DP, Wec AZ, Lilov A, Champney E, Sun T, Archambault K, Burnina I, Lynaugh H, Zhi X, et al: Affinity maturation enhances antibody specificity but compromises conformational stability. Cell Rep 28: 3300-3308. e 4, 2019.

7. Nakamura T, Motoyama T, Hirokawa T, Hirono $S$ and Yamaguchi I: Computer-aided modeling of pentachlorophenol 4-monooxygenase and site-directed mutagenesis of its active site. Chem Pharm Bull (Tokyo) 51: 1293-1298, 2003.
8. Chen JM, Grad R, Monaco R and Pincus MR: Prediction of the three-dimensional structure of the rap-1A protein from its homology to the ras-gene-encoded p21 protein. J Protein Chem 15: 11-15, 1996.

9. Yuan Q, Huang L, Wang X, Wu Y, Gao Y, Li C and Nian S: Construction of human nonimmune library and selection of scFvs against IL-33. Appl Biochem Biotechnol 167: 498-509, 2012.

10. Sircar A: Methods for the homology modeling of antibody variable regions. Methods Mol Biol 857: 301-311, 2012.

11. Nian S, Wu T, Ye Y, Wang X, Xu W and Yuan Q: Development and identification of fully human scFv-Fcs against Staphylococcus aureus. BMC Immunol 17: 8, 2016.

12. Ye Y, Nian S, Xu W, Wu T, Wang X, Gao Y and Yuan Q: Construction and expression of human $\mathrm{scFv}-\mathrm{Fc}$ against interleukin-33. Protein Expr Purif 114: 58-63, 2015.

13. Nigi I, Fairall L and Schwabe JWR: Expression and purification of protein complexes suitable for structural studies using mammalian HEK 293F cells. Curr Protoc Protein Sci 90: 5.28.1-5.28.16, 2017.

14. Portolano N, Watson PJ, Fairall L, Millard CJ, Milano CP, Song Y, Cowley SM and Schwabe JW: Recombinant protein expression for structural biology in HEK 293F suspension cells: A novel and accessible approach. J Vis Exp e51897: 2014.

15. Molek P, Vodnik M, Strukelj B and Bratkovič T: Screening of synthetic phage display scFv libraries yields competitive ligands of human leptin receptor. Biochem Biophys Res Commun 452: 479-483, 2014.

16. Yuan Q, Wang Z, Nian S, Yin Y, Chen G and Xia Y: Screening of high-affinity scFvs from a ribosome displayed library using BIAcore biosensor. Appl Biochem Biotechnol 152: 224-234, 2009.

17. Kahramanoğlu Aksoy E, Akpınar MY, Pirinççi Sapmaz F, Doğan Ö, Uzman M and Nazlıgül Y: Thymic stromal lymphopoietin levels are increased in patients with celiac disease. Bosn J Basic Med Sci 19: 282-287, 2019.

18. Tahaghoghi-Hajghorbani S, Ajami A, Ghorbanalipoor S, Hosseini-Khah Z, Taghiloo S, Khaje-Enayati P and Hosseini V: Protective effect of TSLP and IL-33 cytokines in ulcerative colitis. Auto Immun Highlights 10: 1, 2019.

19. Borowski A, Vetter T, Kuepper M, Wohlmann A, Krause S, Lorenzen T, Virchow JC, Luttmann W and Friedrich K: Expression analysis and specific blockade of the receptor for human thymic stromal lymphopoietin (TSLP) by novel antibodies to the human TSLPR $\alpha$ receptor chain. Cytokine 61: 546-555, 2013.

20. Yazdi IK, Taghipour N, Hmaidan S, Palomba R, Scaria S, Munoz A, Boone TB and Tasciotti E: Antibody-mediated inhibition of Nogo-A signaling promotes neurite growth in PC-12 cells. J Tissue Eng 7: 2041731416629767, 2016.

21. Hafeez U, Gan HK and Scott AM: Monoclonal antibodies as immunomodulatory therapy against cancer and autoimmune diseases. Curr Opin Pharmacol 41: 114-121, 2018.

22. Moutel S, Bery N, Bernard V, Keller L, Lemesre E, de Marco A, Ligat L, Rain JC, Favre G, Olichon A and Perez F: NaLi-H1: A universal synthetic library of humanized nanobodies providing highly functional antibodies and intrabodies. Elife 5: e16228, 2016.

23. Townsend S, Fennell BJ, Apgar JR, Lambert M, McDonnell B, Grant J, Wade J, Franklin E, Foy N, Ní Shúilleabháin D, et al: Augmented binary substitution: Single-pass CDR germ-lining and stabilization of therapeutic antibodies. Proc Natl Acad Sci USA 112: 15354-15359, 2015 .

24. Rodgers KR and Chou RC: Therapeutic monoclonal antibodies and derivatives: Historical perspectives and future directions. Biotechnol Adv 34: 1149-1158, 2016.

25. Nian S, Zhu J, Yu H, Chen Q, Ye Y, Cao X and Yuan Q: Development and identification of a fully human single-chain variable fragment 29 against TSLP. Biotechnol Appl Biochem 66: 510-516, 2019.

26. Zahnd C, Spinelli S, Luginbühl B, Amstutz P, Cambillau C and Plückthun A: Directed in vitro evolution and crystallographic analysis of a peptide-binding single chain antibody fragment (scFv) with low picomolar affinity. J Biol Chem 279: 18870-18877, 2004.

27. Lewis CM, Hollis GF, Mark GE III, Tung JS and Ludmerer SW: Use of a novel mutagenesis strategy, optimized residue substitution, to decrease the off-rate of an anti-gp120 antibody. Mol Immunol 32: 1065-1072, 1995. 
28. Tiller KE, Chowdhury R, Li T, Ludwig SD, Sen S, Maranas CD and Tessier PM: Facile affinity maturation of antibody variable domains using natural diversity mutagenesis. Front Immunol 8: 986, 2017.

29. Zhang YF and Ho M: Humanization of high-affinity antibodies targeting glypican-3 in hepatocellular carcinoma. Sci Rep 6: $33878,2016$.

30. Ahmed M, Cheng M, Zhao Q, Goldgur Y, Cheal SM, Guo HF Larson SM and Cheung NK: Humanized affinity-matured monoclonal antibody $8 \mathrm{H} 9$ has potent antitumor activity and binds to FG loop of tumor antigen B7-H3. J Biol Chem 290: 30018-30029, 2015.

31. Subedi GP, Johnson RW, Moniz HA, Moremen KW and Barb A: High yield expression of recombinant human protein with the transient transfection of HEK293 cells in suspension. J Vis Exp e53568: 2015 .
32. Mitchell PD, El-Gammal AI and O'Byrne PM: Emerging monoclonal antibodies as targeted innovative therapeutic approaches to asthma. Clin Pharmacol Ther 99: 38-48, 2016.

33. Cohan SL, Lucassen EB, Romba MC and Linch SN: Daclizumab: Mechanisms of action, therapeutic efficacy, adverse events and its uncovering the potential role of innate immune system recruitment as a treatment strategy for relapsing multiple sclerosis. Biomedicines 7: E18, 2019.

(i) (9) This work is licensed under a Creative Commons Attribution-NonCommercial-NoDerivatives 4.0 International (CC BY-NC-ND 4.0) License. 